Goldschmidt2020 Abstract

\title{
Applying Stable Isotopes for Source Fingerprinting of Dissolved Organic Nitrogen in Groundwater
}

\author{
Xiaoqin $\mathrm{Wu}^{1}$, Dominique Joyner ${ }^{2}$, Terry C Hazen ${ }^{2}$, Ria Gracielle Malana ${ }^{1}$, Romy Chakraborty ${ }^{1}$ \\ ${ }^{1}$ Lawrence Berkeley National Lab, Berkeley, CA 94720 \\ ${ }^{2}$ Oak Ridge National Lab, Oak Ridge, TN 37830 \\ http://enigma.lbl.gov
}

\begin{abstract}
Dissolved organic nitrogen (DON) constitutes a major pool of dissolved $\mathrm{N}$ in many aquatic ecosystems, playing an important role in biogeochemical cycling of both carbon (C) and N. Our recent work on sedimentary natural organic matter at Oak Ridge FRC site indicated that dissolved DON contributes to more than $50 \%$ of dissolved $\mathrm{N}$ pool in FRC uncontaminated sediments, serving as an important source of $\mathrm{C}$ and $\mathrm{N}$ for microbes when labile $\mathrm{C}$ is limiting. Variations in the natural source determine the quantity and quality of DON in groundwater, and therefore greatly affect the microbial turnover of DON, and resultant microbial community structure. Stable isotope signature at natural abundance is a powerful tool in source fingerprinting of bulk $\mathrm{C}$ and $\mathrm{N}$ in soil and sediment, as well as nitrate in aquatic environments. However, only a handful of studies have been reported on isotopic survey of DON in marine, lake, and soil environments. No reports are available for groundwater thus far.

To obtain baseline information of DON in Oak Ridge FRC groundwater, we investigated the quantity and quality of DOC and DON in groundwater during a 2-month sampling campaign, carried out in spring 2019 (mid March to mid May) at both FRC uncontaminated background area and nitrate contaminated area. Both DOC and DON content in nitrate-contaminated wells during late campaign period (mid April to mid May) was significantly lower $(p<0.05)$ than those during early campaign period (mid March to mid April). This could likely be explained by dilution by water from melting existing snowpack on ground. DOM quality in groundwater changed during this period as well. We used the ratio of $\mathrm{ON}$ to $\mathrm{OC}(\mathrm{ON} / \mathrm{OC})$ as an indicator of DOM quality. During late campaign period (mid April to mid May), the $\mathrm{ON} / \mathrm{OC}$ decreased in nitrate-contaminated groundwater, indicating that water input from melting snowpack potentially introduces different types of DOM (N-poor molecules) to nitratecontaminated groundwater.

Following up on these observations we are developing a reliable analytical method to measure $\mathrm{N}$ isotope signature of trace level of DON in groundwater. Currently, there is no well-established method for directly measuring $\delta^{15} \mathrm{~N}-\mathrm{DON}$ in environmental water sample. We are developing a solid-phase extraction (SPE) based method to concentrate trace level of DON from groundwater and to eliminate interference from inorganic $\mathrm{N}$ such as nitrate and ammonium. Preliminary result shows that $\mathrm{C} 18$ sorbent may absorb or retain $25 \%$ of DON and almost zero inorganic $\mathrm{N}$ from water sample. We are testing more types of sorbent, and will apply Elemental Analyzer-Isotope Ratio Mass Spectrometry (EA-IRMS) for measuring $\delta^{15} \mathrm{~N}-\mathrm{DON}$ in the sorbents.

The source fingerprinting approach developed in this work will extend capabilities of geochemists in examining the changes in key geochemistry (e.g., quantity and quality of DON) under changing seasonal and hydrologic conditions, and benefit microbiologists for predictive understanding of how seasonal dynamics in DON property influence natural microbial communities.
\end{abstract}

Funding Statement: This material by ENIGMA- Ecosystems and Networks Integrated with Genes and Molecular Assemblies (http://enigma.lbl.gov), a Scientific Focus Area Program at Lawrence Berkeley National Laboratory is based upon work supported by the U.S. Department of Energy, Office of Science, Office of Biological \& Environmental Research under contract number DE-AC02-05CH11231 